\title{
Grazing Incidence Mirrors for EUV Lithography
}

\author{
Mariana Braic, Mihai Balaceanu and Viorel Braic \\ National Institute for Optoelectronics \\ Romania
}

\section{Introduction}

The ongoing development of the knowledge-based society has brought about new challenges derived from the increasing volume and complexity of the information resources available. For a faster and more affordable transfer and processing of information, further progress is resting upon the development of increasingly smaller, higher density, integrated microelectronics, and their availability at lower prices.

The actual industrial standard governing the manufacture of microprocessors, employing today's deep-ultraviolet lithography (DUVL), is limited by the minimum wavelength of 193 nm.

As microprocessor feature size continues to decrease to sub-45 $\mathrm{nm}$ levels, greater spatial resolution is needed to be obtained. In an optical lithographic system the critical dimension is determined by the Rayleigh criterion, so that in order to obtain a smaller critical dimension one can increase the numerical aperture while maintaining the conventional lithographic wavelength of $193 \mathrm{~nm}$. This approach permitted to obtain feature size less than 45-nm [Rothschild et al., 2005]. However, the increased demands on the miniaturisation have already reached the limits of the DUVL. Considering the Rayleigh criterion, another possible approach to minimize the critical dimension is to decrease the radiation wavelength. This idea is materialised as the Extreme-Ultraviolet Lithography (EUVL), using a wavelength of $13.5 \mathrm{~nm}$ [Stulen \& Sweeney, 1999].

In Europe, ASML and its main co-developer Carl Zeiss, are heavily investing in the development of key technological issues, aiming for the realization of an EUVL $\alpha$-tool [Meiling et al., 2003], [Meiling et al., 2005], for subsequent world-wide commercialization [ASML, 2009], while in USA, SEMATECH organization has the leading role [SEMATECH, 2009].

EUVL is a domain undergoing intensive research at the moment, as one of the leading candidates among emerging lithography techniques, enabling $35 \mathrm{~nm}$ half-pitch patterning and providing also extendibility to $22 \mathrm{~nm}$, using a solely reflective optics.

The requirement for the replacement of transmitting lenses with reflecting mirrors within the patterning tool is due to the strong absorption of the EUV light in most of materials gases included, a high reflection coefficient being difficult to obtain at either near grazing or near normal incidence angles. The requirement for an entirely reflective optics, placed in vacuum, introduces numerous technological challenges, as well as the requirement to efficiently generate 13.5-nm light, with high intensity and high reliability.

The EUV source specifications are derived, accordingly to the existing standards in visible and DUV lithography, from the customer requirements: high throughput - more than 100 wafers / hour, imaging quality and cost of ownership. To generate EUV light, hot and dense Source: Lithography, Book edited by: Michael Wang,

ISBN 978-953-307-064-3, pp. 656, February 2010, INTECH, Croatia, downloaded from SCIYO.COM 
plasmas are required. EUV radiation is generated using gas-discharge-produced plasmas (DPPs), laser produced plasmas (LPPs) with ultra-fast lasers, synchrotron or X-ray radiation [Stamm, 2004].

EUVL systems using LPPs and DPPs sources rely on optical configurations including collection and projection modules composed by grazing and near incidence reflective mirrors [Singh \& Braat, 2000], [Bakshi, 2006]. In a LPPs-based system, EUV light is produced by bombarding a sliver of Sn with a high-power laser, while in a DPPs system the EUV light emerges from Xe plasma, enriched with metal EUV radiators, as Li and Sn [Banine \& Moors, 2004]. The EUV light produced by either source is being collected by specially engineered EUV mirrors, which then focus the EUV beam in the EUV scanner to produce microchip patterns.

The main aspects to be addressed by the source specification are: the operating wavelength, the EUV power, the hot spot size, the collectable angle, the repetition rate, the pulse-to-pulse repeatability and the debris induced lifetime of components. While the first requirements are addressing only the EUV plasma source engineering, the last one deals also with the engineering of the optical system, mainly with the collector system - optical design and materials to be used. The mirrors responsible for collecting the light are directly exposed to the plasma and are therefore vulnerable to the damage done by the high-energy ions [Komori et al., 2004], [Hansson et al., 2002], and other debris [Srivastava et al., 2007]. These damage associated with the high-energy process of generating EUV radiation have precluded the successful implementation of practical EUV light sources for lithography. This chapter addresses the issues related to the attainability of high reflectivity grazing incidence collection mirrors with extended life time, to be used in EUVL systems.

\section{Requirements for the collection optics in EUVL}

In the lithographic process of patterning fine-scale structures onto a substrate, the radiation used to selectively expose the recording medium (resist) can be optical, e-beam, X-ray or ion beam. If the optical radiation is used, including DUV and EUV, the lithographic system consists of four main elements, integrated in an unique optical system [Jaeger, 2002]:

a. light source;

b. mask containing the patterns corresponding to the structures to be fabricated;

c. exposure system to generate an aerial image of the mask pattern and

d. resist, for recording the image generated by the exposure system.

In the EUV lithographic systems, there are two more modules to be integrated in the optical system: the collector and the projection modules [Bakshi, 2006].

Concerning the light source, up to date, the most used EUV light sources are the DPPs ones. These sources are reported to generate more power, consume less energy, being less expensive. As a result, this type of source was integrated into alpha-level EUVL scanners. Also, the low power version of DPPs source has been used in EUV micro-exposure tools, in industrial EUV metrology and EUV resist development projects [Lebert et al., 2003], [Song et al., 2006], [Bolanti et al., 2003], [Zuppella et al., 2009] and [Fiedorowicz et al., 2005]. This type of source was used also in the development and testing of the grazing incidence mirrors presented in the following [Choi et al., 2004].

The part of the EUV optical system including the mirrors, which are designed to collect as much as possible EUV light produced by the source, is known as the collector module, while the mirrors designed to focus the EUV light on the resist, are part of the projection module. 
Apart from the mirrors, the optics may comprise also filters for cutting the wavelengths higher than $40 \mathrm{~nm}$. The mask is part of the exposure system, including the resist exposure stage, with movement control in the Angstrom range [Itani, 2009], [Wallace et al., 2007].

Due to the strong absorption of EUV light in any material, including gases (even at pressures in the Pa range), in an EUVL system all the components must reside in high and clean vacuum. The EUV light source it-self represents the cause of important demands on the EUV optics geometry and materials to be used, as the heat and debris emerging from it can seriously damage the optics facing the source. Usually the EUVL optics is protected from the energetic debris from the source using gas (He) curtains, electrostatic and mechanical shields [Vargas-Lopez et al., 2005], [Bakshi, 2006].

The collection mirrors must have high reflectivity at grazing angles, high resistance to the energetic particle bombardment, high adhesion to the substrate and a high stability in a wide range of temperatures, as the heat load from the entire radiation emitted by the EUV source is important. The overall reflectivity of EUV mirrors, especially of those in the collection module, is under continuous degradation due to erosion and contamination from within the EUV source, as $\mathrm{Xe}, \mathrm{Li}$ and $\mathrm{Sn}$ are the conventional, currently used, EUV light fuel [Allain et al., 2008]. This is a matter of great concern because it directly affects the available power of the EUV source, and thus the final cost of production [Neumann et al., 2007], [Bakshi, 2006].

The collector mirrors are facing a continuous bombardment of debris emerging from EUV light sources, fast ions, neutrals, off-band radiation, droplets, and background impurities (i.e., $\mathrm{H}, \mathrm{C}, \mathrm{N}, \mathrm{O}$ ), as well as the heat load generated by the sources themselves, all of them inducing serious damage to the nearby collector mirrors. The challenge is to obtain a collection mirror exhibiting high reflectivity at grazing incidence angles, high resistance to the bombardment done by energetic particles, micro-chemical stability at high temperatures and corrosion resistance, combined with small roughness, so as to prevent significant radiation loss via scattering.

\section{Materials for EUV mirrors}

The materials used for manufacturing the EUVL mirrors must have some valuable properties, as [Shin et al., 2009], [Hecquet et al., 2007]:

- manufacturing design freedom of shape and size;

- sustaining of polishing procedures, up to a tenth of a nanometre for the final roughness, because the roughness became a very sensitive parameter to be considered, as the wavelength decreases;

- low coefficient for thermal expansion (CTE), in order to reduce the optics distortion due to geometrical factors.

There are several types of such materials, as the well known silica and quartz, or the recently developed zerodur (lithium aluminosilicate glass-ceramic) and ULE (a titania-silica binary glass with zero CTE). The bare surfaces of these materials are presenting lower reflectivity values for grazing incidence, as compared to most of the metallic surfaces, considering the same surface roughness.

An all reflective optical system can have either only near normal incidence mirrors, or a combination of grazing incidence and near normal incidence mirrors. In order to choose the best materials, modelling the EUV light interaction with matter is a valuable tool. The wavelength domain to be considered is centred near-by the value where the maximum EUV throughput is obtained from the EUV sources, e.g. $13.5 \mathrm{~nm}$ [Bakshi, 2006]. In the following all the materials will be considered with respect to their properties at this specific wavelength. 
The interaction with matter of the soft X-ray and EUV radiation (in the range $1-40 \mathrm{~nm}$ ), in terms of transmission or reflectivity, can be "experienced" by using the free on-line connection to the Center for X-Ray Optics, a facility within the Materials Science Division at Lawrence Berkeley National Laboratory, USA [CXRO, 2009]. The details about the interactions of the soft X-rays with matter (photoabsorption and the coherent scattering) are clearly explained [CXRO, 2009]. The basic assumption made is considering the condensed matter as a collection of non-interacting atoms, a condition fulfilled for energies sufficiently far from the absorption thresholds, while in the threshold regions, the specific chemical state become important, so that direct experimental measurements are to be used. The inelastic Compton scattering cross section has not been included in the reflectivity calculations, as the Compton cross section contribution is significant only for light elements $(Z<10)$ at energies higher than $10 \mathrm{keV}$ [Hubbell et al., 1975]; Hubbell et al., 1977].

Using the CXRO facility, one can easily obtain the ideal values for the EUV radiation reflectivity on a certain surface. For near-normal incidence mirrors, an enhancement of the reflectivity is obtained if we consider a typical Bragg reflector, in which the thickness of each layer is approximately a quarter-wave. Although the reflectivity of a single transition from a layer to another one is very small, the addition of multiple reflections results in a saturation to a maximum reflectivity. In EUV optics there are used multilayers (ML) formed by materials with alternate high and low absorption coefficients [Gloecker \& Shah, 1995]. In $\mathrm{EUV}$, the light absorption is directly linked with the $\mathrm{Z}$ value of the considered material. The best known near-normal incidence mirrors for EUVL are made from 40 to 60 bi-layers of Mo (on top) and $\mathrm{Si}$ (on bottom part), the bi-layer period being $6.9 \mathrm{~nm}$. Another important parameter to be considered is the ratio of the bottom layer thickness to the overall bi-layer thickness, which in this case have the value $\Gamma=0.4$. The ideal reflectivity of such a mirror is about $72 \%$ at normal incidence (with respect to the surface, not to the surface normal, as in VIS optics) [Benoit et al., 2006], [Wang et al., 2006], [Fiegl et al., 2006], [Schroeder et. al., 2007].

However, these mirrors are very sensitive to the oxidation, contamination, and the reflectivity is decaying in time, due to the mixing of the individual layers, the mechanism being diffusion driven. In fig. 1 is presented, comparatively, the ideal reflectivity obtained by simulation [CXRO, 2009] for a Mo/Si multi-layered mirror, with 60 bi-layers, with no inter-diffusion (Fig. $1 \mathrm{a}-\mathrm{s}=0$ ) and with layers inter-diffusion of $1 \mathrm{~nm}$ (Fig. $1 \mathrm{~b}-\mathrm{s}=1$ ). It can be observed that not only the maximum reflectivity value is decreased, but also the maximum is shifting towards lower wavelengths, generating an overall loss of EUV light in the system. Due to the specific pattern obtained for the reflectivity of this multilayered mirror, it's role in the EUVL system is also to create a highly monochromatic radiation, by the repetitive reflection on several mirrors. As presented above, at this wavelength is also obtained the maximum EUV intensity from the $\mathrm{Xe}$, Li or Sn radiators used in either DPPs or LPPs EUV sources.

Concerning the reflectivity at grazing incidence, from the system's geometry, it results that the angle to be considered for the reflectivity modelling is about $6^{0}$, with respect to the surface. In Fig. 2 are presented the ideal values obtained by using the CXRO facility, for the reflectivity at $\lambda=13.5 \mathrm{~nm}$, at $6^{0}$ incidence with respect to the surface, for the most used materials in optics (silica, quartz, zerodur and ULE), and in Fig. 3 are presented the ideal reflectivity of some thick metallic layers. As expected the metallic surfaces present a much higher reflectivity for EUV light, as compared with the materials used as substrates, due to the different electronic configurations of these types of materials. 
$\mathrm{Si} / \mathrm{Mo} \mathrm{d}=6.9 \mathrm{~nm} \mathrm{~s}=0 . \mathrm{nm} \mathrm{N}=60$ at $90 . \mathrm{deg}, \mathrm{P}=0$.

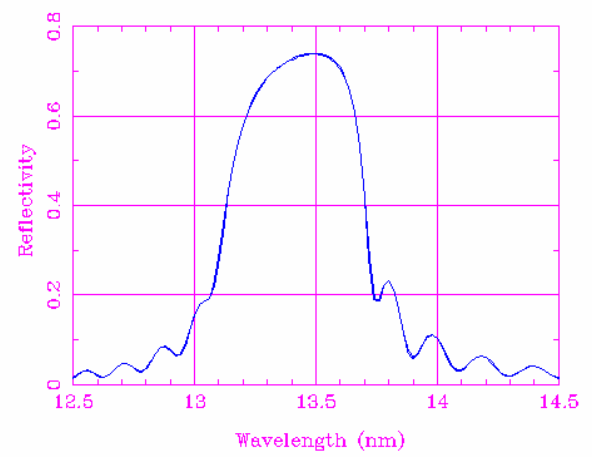

(a)
$\mathrm{Si} / \mathrm{Mo} \mathrm{d}=6.9 \mathrm{~nm} \mathrm{~s}=0.8 \mathrm{~nm} \mathrm{~N}=60$ at $90 . \operatorname{deg}, \mathrm{P}=0$.

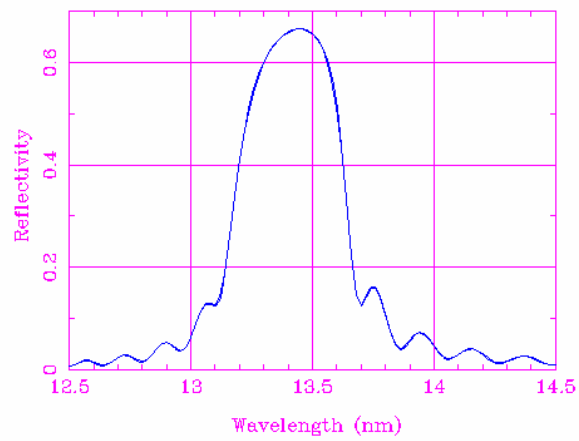

(b)

Fig. 1. Ideal reflectivity at normal incidence of a Mo/Si multi-layered mirror, with $60 \mathrm{bi}-$ layers, with (a) no inter-diffusion $(\mathrm{s}=0 \mathrm{~nm})$ and $(\mathrm{b})$ an inter-diffusion zone of $1 \mathrm{~nm}(\mathrm{~s}=1 \mathrm{~nm})$.

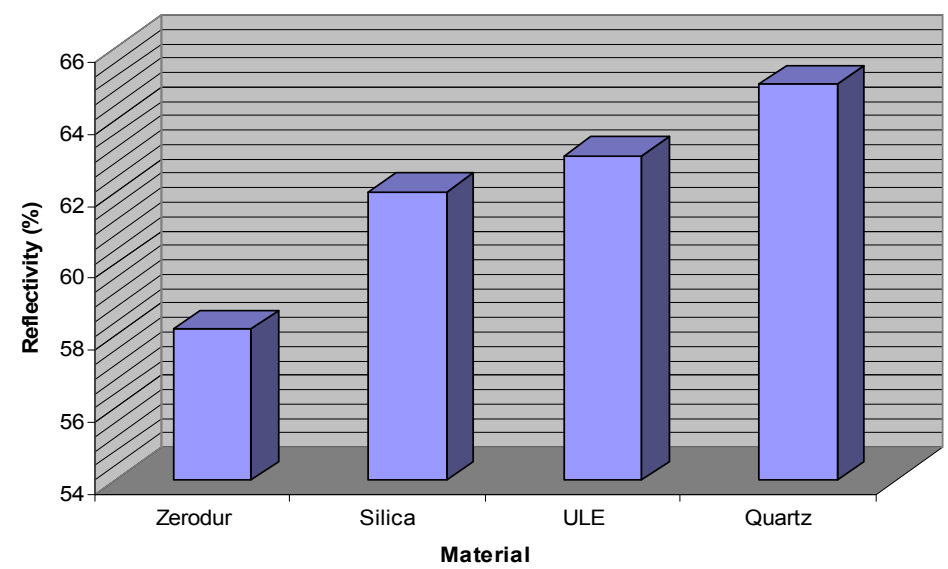

Fig. 2. Ideal reflectivity values, at $\lambda=13.5 \mathrm{~nm}, 6^{0}$ incidence with respect to the surface, for silica, quartz, zerodur and ULE

Up to date, the EUV mirrors are usually made from special substrate materials as ULE or zerodur, subsequently coated with metallic thin films selected to be highly reflective in 12-15 $\mathrm{nm}$ domain, having a relatively high native oxidation resistance, e.g. palladium, ruthenium, and rhenium [Bakshi, 2006], [Alman et.al., 2007].

The new approach considered by the authors is to substitute the metallic coatings with covalent type materials, such as transitional metal carbides and nitrides thin films, with low surface roughness values $(<0.5 \mathrm{~nm})$, which exhibit high reflectivity at $13.5 \mathrm{~nm}$ [Braic et al., 2005], [Braic et al., 2004], [Braic et al., 2008].

The nitrides and carbides of the transitional metals are well known for their stable microchemical properties at high temperatures, high oxidation resistance, high melting point, high hardness, high toughness and Young's modulus, high electric conductivity, excellent chemical stability, together with good wear resistance and high adhesion onto different 


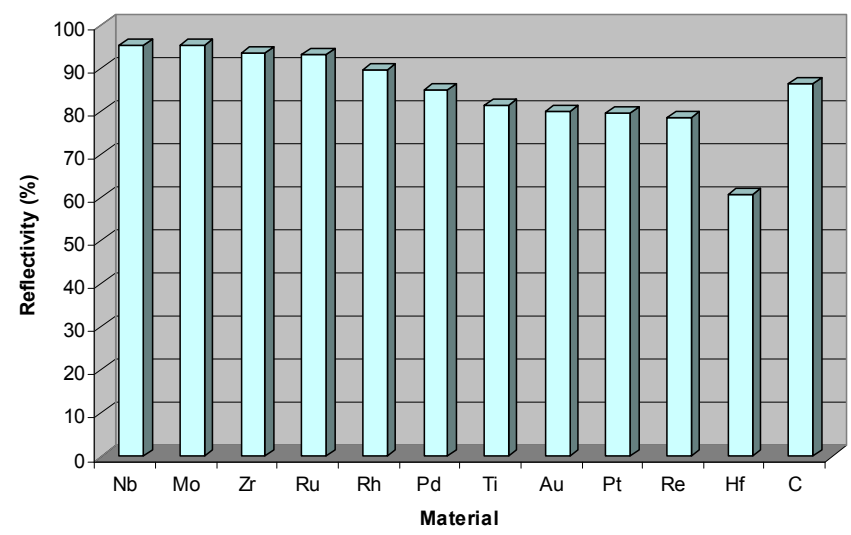

Fig. 3. Ideal reflectivity values, at $\lambda=13.5 \mathrm{~nm}$ and $6^{0}$ incidence with respect to the surface, for some thick metallic layers

substrates [Barshilia \& Rajam, 2006], [Ducros \& Sanchette, 2006], [Braic et al., 2006]. Their chemical inertness and high hardness is linked to their predominant covalent type bonding. Group IV - VI transitional metals are forming nitride and carbide compounds characterized by a large number of nitrogen/carbon vacancies. It is known that the nitride/carbides of the group IV metals ( $\mathrm{Ti}, \mathrm{Zr}$ and $\mathrm{Hf}$ ) can crystallize only in the cubic $\mathrm{NaCl}$ (FCC) structure, while the metals form the group $\mathrm{V}(\mathrm{Nb}, \mathrm{Ta})$ and $\mathrm{VI}(\mathrm{Mo})$ can form carbides either in cubic $(\mathrm{MeC})$ or in hexagonal forms $\left(\mathrm{Me}_{2} \mathrm{C}\right)$. While the group IV of metallic carbides can accommodate up to about $50 \%$ vacancies on the non-metal sub-lattices, and still retain their cubic structure, the groups V and VI of metallic nitride/carbides crystallize under different structures, switching from hexagonal to the more stable cubic one, with increased nitrogen/carbon content, the process being also temperature dependent [Hugosson et al., 2001].

Due to their superior stability in their FCC crystallographic structure, there were selected the nitride and carbide of the group IV transitional metals. From the group $\mathrm{V}, \mathrm{Nb}$ compounds are good candidate, but they also present high Young modulus values, so that the adhesion to a non-metallic substrate may develop undesired problems. From the group VI, Mo may also represent a good candidate, but at lower temperatures $\left(<1000^{\circ} \mathrm{C}\right)$ the FCC structure of its compounds tend to transform into a hexagonal or orthorhombic one. Also, the mechanical properties and oxidation resistance are less performing if compared to those exhibited by the compounds of the group $\mathrm{V}$ transitional metals, probably due to its large ionic component, compared to the covalent one [Kanoun et al., 2007].

In fig. 4 are presented the ideal values obtained by using the CXRO modelling facility, for the reflectivity at $\lambda=13.5 \mathrm{~nm}$, at $6^{0}$ incidence angle with respect to the surface, for the nitride and carbide compounds of $\mathrm{Ti}, \mathrm{Zr}$ and Hf.

From the results presented above, it results that the best coatings to be used as grazing mirrors in the EUV collector system, are the $\mathrm{Zr}$ based carbide and nitride films. However, one major problem to be tackled in this application is the requirements to obtain coatings with high adhesion to the substrate, and with a reduced mechanical intrinsic stress, which is known to build-up during the growth process. There are several strategies used for reducing the stress: ion bombardment during growth [Vladescu et al., 2007], moderate substrate temperature during film deposition, use of a substrate with a CTE similar to 


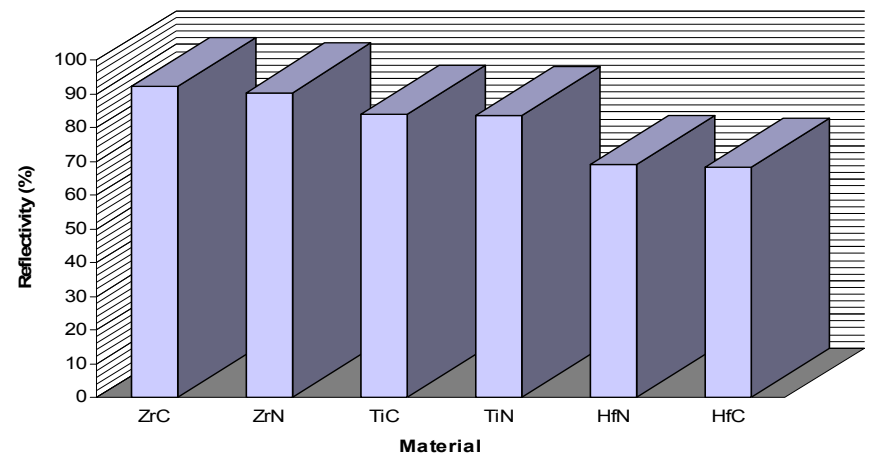

Fig. 4 . Ideal reflectivity values at $\lambda=13.5 \mathrm{~nm}$ and $6^{0}$ incidence with respect to the surface, for $\mathrm{Ti}, \mathrm{Zr}$ and $\mathrm{Hf}$ nitrides and carbides

that of the film to be deposited. All these are currently used during films' deposition, however the films are still not stress-free.

Another approach is to use multi-layered (ML) films, as this kind of structure is known to inhibit cracks propagation and to have a low level of residual stress, a high adhesion strength and very high microhardness values, superior to those of the component layers [Helmersson et al., 1987], [Yashar \& Sproul, 1999], [Musil, 2000], [Vladescu et al., 2008]. This direction is worth to be explored, so that the ideal reflectivity values, at $\lambda=13.5 \mathrm{~nm}$ and $6^{0}$ incidence with respect to the surface, for some ML based on $\mathrm{ZrN} / \mathrm{TiN}$ and $\mathrm{ZrC} / \mathrm{TiC}$ were calculated, the results being presented in Fig. 5.

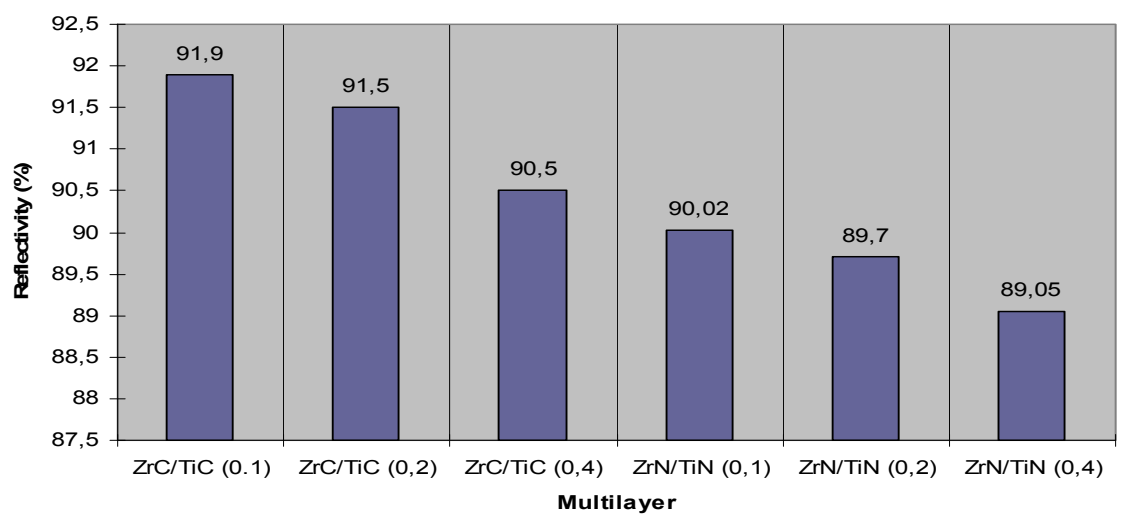

Fig. 5. Ideal reflectivity values at $\lambda=13.5 \mathrm{~nm}$ and $6^{0}$ incidence with respect to the surface, for multilayered structures based on $\mathrm{ZrN} / \mathrm{TiN}$ and $\mathrm{ZrC} / \mathrm{TiC}$, for $\Gamma=0.1 ; \Gamma=0.2$ and $\Gamma=0.4$.

To illustrate the reflectivity dependence on the surface and interface roughness in Fig. 6 are presented the ideal reflectivity for a $\mathrm{ZrN} / \mathrm{TiN}$ multilayer, $\mathrm{n}=40, \Lambda=7 \mathrm{~nm}, \Gamma=0.1$, either perfectly smooth $(\mathrm{a}-\mathrm{rms}=0 \mathrm{~nm})$ or with a higher roughness at the interfaces between the individual layers $(\mathrm{b}-\mathrm{rms}=0.1 \mathrm{~nm})$.

From the presented results, it clearly results the superiority of Zr based coatings to be used for surface finishing of the collector mirrors used in EUV lithographic systems. 
$\mathrm{ZrN} / \mathrm{TiN} \mathrm{d}=7 . \mathrm{nm} \mathrm{s}=0 . \mathrm{nm} \mathrm{N}=40$ at $6 . \mathrm{deg}, \mathrm{P}=0$.

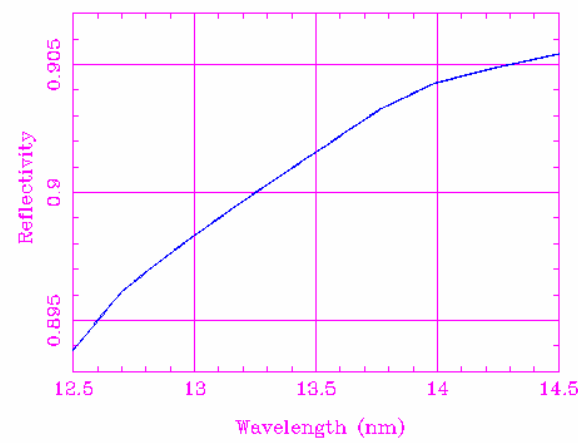

(a)
$\mathrm{ZrN} / \mathrm{TiN} d=7 . \mathrm{nm} \mathrm{s}=0.1 \mathrm{~nm} \mathrm{~N}=40$ at 6 .deg, $\mathrm{P}=0$.

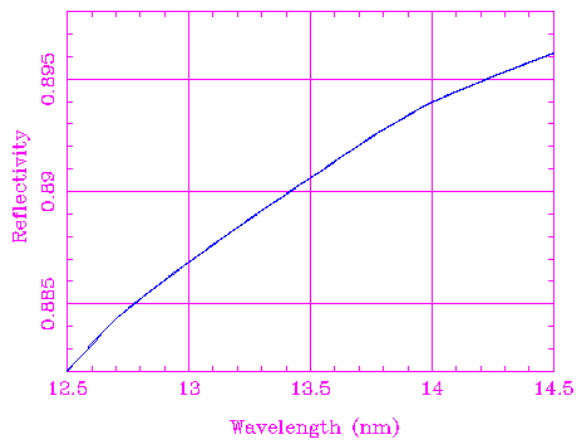

(b)

Fig. 6. Ideal reflectivity of a $\mathrm{ZrN} / \mathrm{TiN}$ multilayered mirror, $300 \mathrm{~nm}$ thickness, with surface roughness $\mathrm{rms}=0 \mathrm{~nm}(\mathrm{a})$ and $\mathrm{rms}=0.1 \mathrm{~nm}(\mathrm{~b})$.

\section{Collector module design with grazing incidence mirrors}

A straightforward approach for the design of the collection optics, based on a wide emission angle of the EUV source, consists of an ellipsoidal configuration, the EUV source being in one focus and in the other one the image for the projection mirror is formed. The collected EUV radiation is focused as a narrow circular shape of illumination at a near-normal incidence angle on to a reflecting Mo/Si spherical mirror. The focused beam resulted from the projection mirror is directed towards the resist through a $\mathrm{Si}_{3} \mathrm{~N}_{4}$ or a $\mathrm{Zr}$ filter to a transmission mask. The role of the filters is to cut the radiation with wavelengths $>20 \mathrm{~nm}$. The design of the first approach for the EUV collector used in our work is presented in Fig.7. As it can be seen, the central cone emerging from the EUV source, which contains the most part of the debris (fast atoms, ions and electrons), is lost. Minimizing the central cone and using a very long ellipsoid ( $1 \mathrm{~m}$ between focal points at $0.12 \mathrm{~m} \mathrm{ID),} \mathrm{a} \mathrm{high} \mathrm{collecting}$ efficiency is obtained.

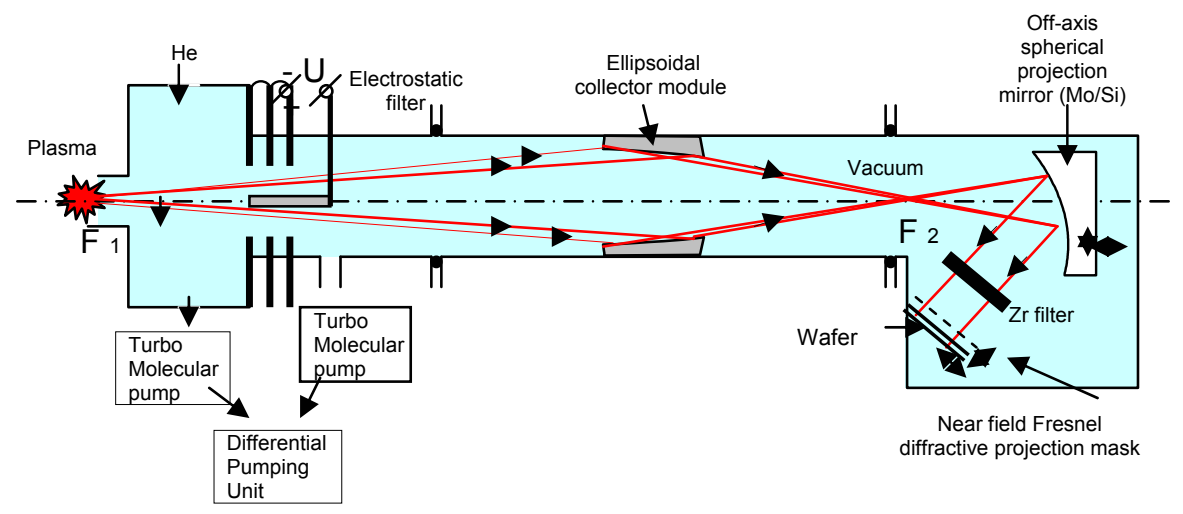

Fig. 7. The design of the first approach for the EUV collector, with ellipsoidal mirrors 
However, in most of the used PDDs EUV sources, the emission of light and debris is directed mainly forward, in a narrow angle. So, an off-axis collection optics allowing the collection of the whole cone is required. In the same ellipsoidal geometry the source is oriented at approx. $10^{0}$ off-axis and points towards a $210 \mathrm{~mm}$ long and $60 \mathrm{~mm}$ wide area, near by the central section of the ellipsoid. The image of the source is formed in the same position (focal point) as in the on-axis configuration. The total length of the optical path, from EUV source to the projection spherical Mo/Si mirror, is approx. $1.4 \mathrm{~m}$, imposing the same length for the vacuum chamber, which has to be pumped according with its volume, with turbo-molecular pumps [Braic et al., 2008].

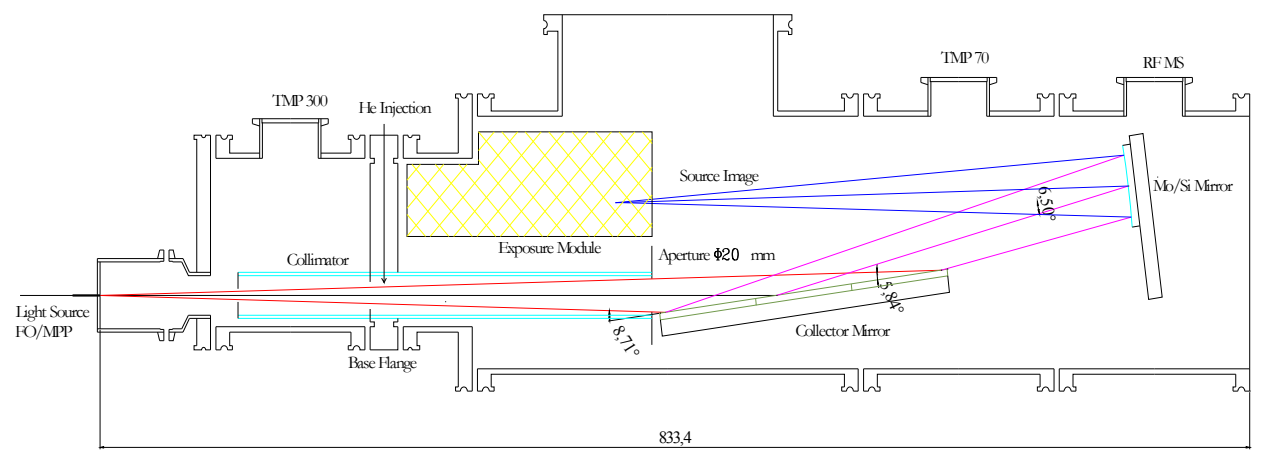

Fig. 8. Schematic view of the off-axis optics and vacuum chamber

The off-axis configuration opened a new opportunity to reduce the optical path, placing the $\mathrm{Mo} / \mathrm{Si}$ mirror between the grazing incidence ellipsoidal surface and the focal point, significantly shortening the length of the optical path to approx. $0.8 \mathrm{~m}$, also offering a significant reduction of the vacuum chamber volume and pumping unit (Fig. 8). The projector is a Mo/Si coated mirror with $13.5 \mathrm{~nm}$ centred wavelength. In the presented configuration, the diameter of the mirror is 2 " and the curvature radius is $500 \mathrm{~mm}$.

Vacuum chamber is designed to be assembled from standard high vacuum stainless steel components ISO 100 and ISO 160. Sealing of the parts is done with fluoro-elastomer gaskets, with very low out-gassing rate. The high and also clean vacuum environment is considered appropriate for the exposure tests. Checking of the residual gas composition is done by an $\mathrm{RF}$ mass spectrometer connected to the exposure chamber. The UHV technology was considered not appropriate, because of the exposure module components, which are not suitable for high temperature baking (up to $250^{\circ} \mathrm{C}$ ). The cleanliness of a vacuum environment is determined by the components and their out-gassing rate under vacuum. The chamber is differentially pumped by turbo pump located near the EUV source exit (mainly for heavy gases - Xe, Ar removing) and by another turbo pump located nearby the optics and exposure module (for He, resist and other components effluents). The turbo pumps are backed by mechanical dry rotary pumps.

One requirement from the EUVL optics is to minimize the contamination of the Mo/Si sensible mirrors due to the debris or effluents resulted from the used components, e.g. resist, fixture materials, etc [Shin et al., 2009]. As a result, the use of any coating including carbon was dismissed for further work related to EUV mirrors [Braic et. al., 2009] despite their valuable properties [Balaceanu \& Braic, 2005]. 


\section{Coatings' deposition for the grazing incidence mirrors}

The coatings were deposited on optical glass, $\mathrm{Si}$, plain carbon steel and high-speed steel substrates by bi-bipolar pulsed reactive magnetron sputtering method, using $\mathrm{Ti}$ and $\mathrm{Zr}$ cathodes and a reactive atmosphere consisting of a mixture of $\mathrm{N}_{2}$ and Ar gases. The deposition set-up is presented schematically in Fig. 9.

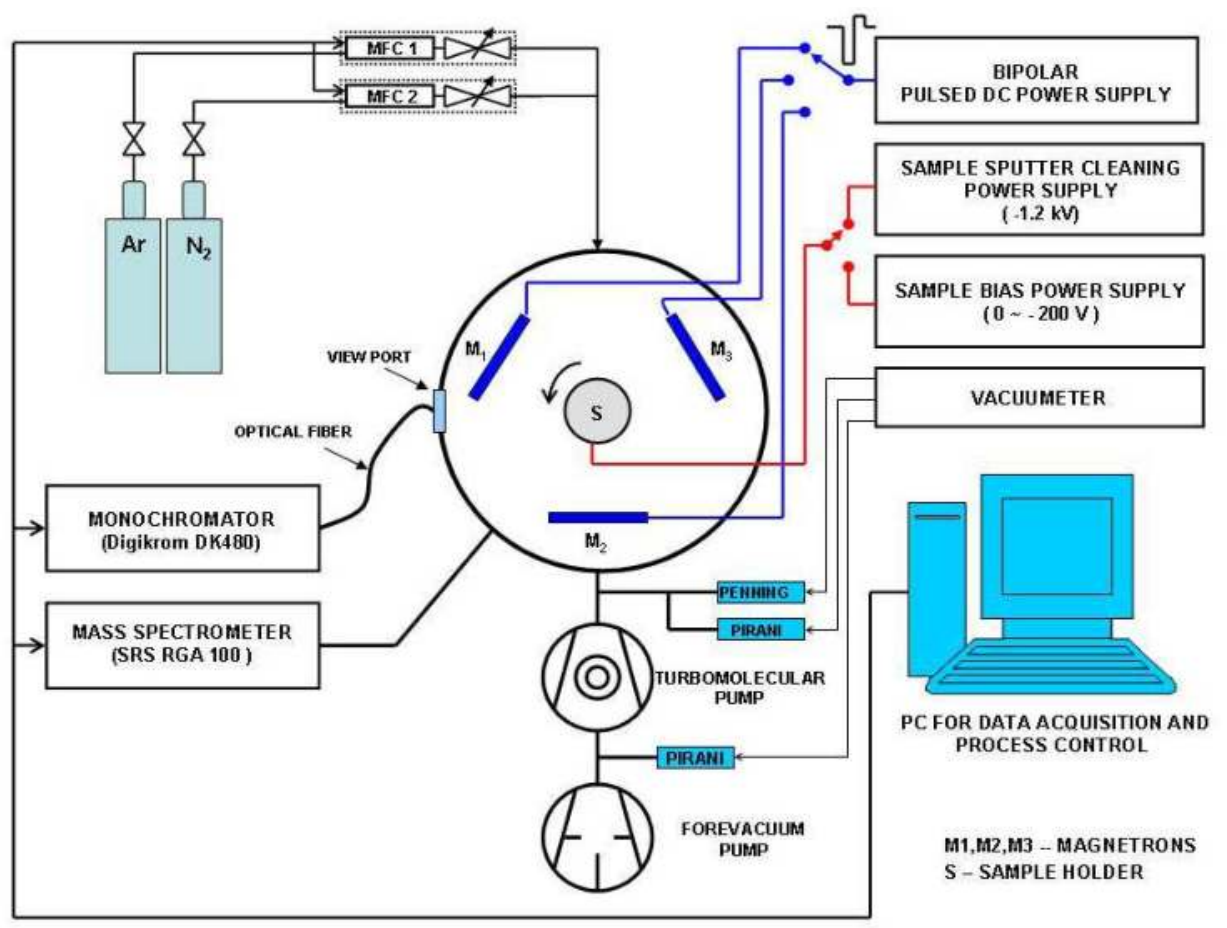

Fig. 9. Deposition chamber set-up for the multilayered coatings

The deposition cylindrical chamber (300 mm internal diameter and $500 \mathrm{~mm}$ height) has three rectangular $\left(140^{\star} 250 \mathrm{~mm}\right)$ magnetron targets.

The Ti and Zr cathodes were fed using a pulsed bipolar generator - type ENI RPG5, to avoid the problems related to the target poisoning during reactive deposition. The magnetron discharges are fed by a two channel Brooks 502 mass low controller with argon and nitrogen. The argon is introduced by pipes in front of each magnetron target and the nitrogen is directed towards the substrates.

The substrate holder assembly includes a thermocouple for temperature measurement during the deposition, is electrically insulated and provides the rotation of the individual sample holders. The rotation is provided by a stepper motor in order to have a computer controlled rotation speed and also to move the substrates in front of the two different targets.

The main deposition parameters were: deposition pressure $-4 \cdot 10^{-1} \mathrm{~Pa}$, substrate bias $-50 \mathrm{~V}$, ratio of $\mathrm{N}_{2}$ and Ar partial pressures - 0.37. 
The distance from any of the cathodes to the substrate holder is $10 \mathrm{~cm}$. The UHV vacuum system ensures a base pressure in the deposition chamber was of about $1 \times 10^{-5} \mathrm{~Pa}$. The absolute pressure was measured with a MKS 626 Barocel capacitance manometer.

To obtain alternated $\mathrm{ZrN} / \mathrm{TiN}$ films, two shutters placed in front of each magnetron were used. By periodically opening and closing the shutters and rotating the substrates in front of the active magnetron, $\mathrm{Ti}$ and $\mathrm{Zr}$ ions/atoms sputtered from the magnetrons were alternatively introduced in the deposition atmosphere for a predetermined time. Depending on the deposition rates, previously measured for each type of monolayer ( $\mathrm{TiN}$ and $\mathrm{ZrN}$ ), and on the rotating speeds of the shutters, various multilayer configurations (with different bilayer thicknesses $\Lambda$ and $\Gamma$ parameter) were prepared.

Following the information obtained by simulation, multilayer with a constant $\Gamma$ value, equals to 0.1 , and different thicknesses of the bilayer, were deposited. In order to differentiate between the different types of ML, the notation $\mathrm{ZrN} / \mathrm{TiN}-\mathrm{n} / \Lambda$ will be used, where " $n$ " is the number of bi-layers and " $\Lambda$ " is the bi-layer thickness.

Different overall thicknesses of the coatings were deposited, depending on the tests taken into account: for EUV reflectivity measurements and surface roughness evaluation, the thickness was of about $280 \mathrm{~nm}(\mathrm{n}=40 ; \Lambda=7 \mathrm{~nm})$, while for elemental, structural and mechanical characterisation the total thickness was much greater, of about $3500 \mathrm{~nm}(\mathrm{n}=500$; $\Lambda=7 \mathrm{~nm})$.

Prior to deposition, specimens to be coated were chemically cleaned in an ultrasonic bath with isopropyl alcohol. Both the substrates and the magnetron targets were sputter cleaned in vacuum by $\mathrm{Ar}$ ion bombardment $(1200 \mathrm{eV})$ for 10 minutes, in order to remove any residual impurities.

To ensure the deposition of stoichiometric layers, the optical emission spectroscopy (OES) was done, by on-line monitoring of the $\mathrm{Zr}$, Ti and $\mathrm{N}_{2}{ }^{+}$lines emitted by the discharge, by using a monochromator (Digikrom DK480), equipped with an R446 Hamamatsu photomultiplier. The acquisition, storage and processing of the spectra were performed by an Advantech 818 data acquisition system. The light signal emitted by the plasma was transmitted to the monochromater, through a quartz window and a collimator positioned in front of the target, by using an optical fibre. Concomitantly, the process gases were monitored by RF mass spectrometry (SRS RGA 100), in order to maintain a fine balance between the argon and nitrogen in the deposition chamber.

In magnetron sputtering deposition of nitrides ( $\mathrm{TiN}, \mathrm{ZrN}$ ), the ratio of $\mathrm{Ar} / \mathrm{N}_{2}$ partial pressures in the working gas determines two working regimes with different sputtering yield of the cathode's material under ion bombardment, affecting the film's stoichiometry. During the deposition, the compound deposited onto the substrates is also deposited on the cathode, so the decrease of cathode sputtering yield, of about 5 times, is observed.

The transition between the "metallic" and the "ceramic" modes takes place abruptly at a small change of nitrogen flow (small increase of the nitrogen content in the working atmosphere). The continuous monitoring of the relative intensity of a metallic line (Ti or/ $\mathrm{Zr}$ ) shows a sharp decrease in the transition region. By continuously monitoring the metallic lines, any small tendency of decrease, is followed by a command to either decrease the nitrogen flow or increase the current fed on magnetron. The optimized conditions were established for $\mathrm{TiN}$ and $\mathrm{ZrN}$ single layers. In Fig. 10 is presented the variation of the Ti line intensity $(\mathrm{Ti}-\lambda=468.19 \mathrm{~nm}$ ) at the nitrogen flow increase in the deposition system. 


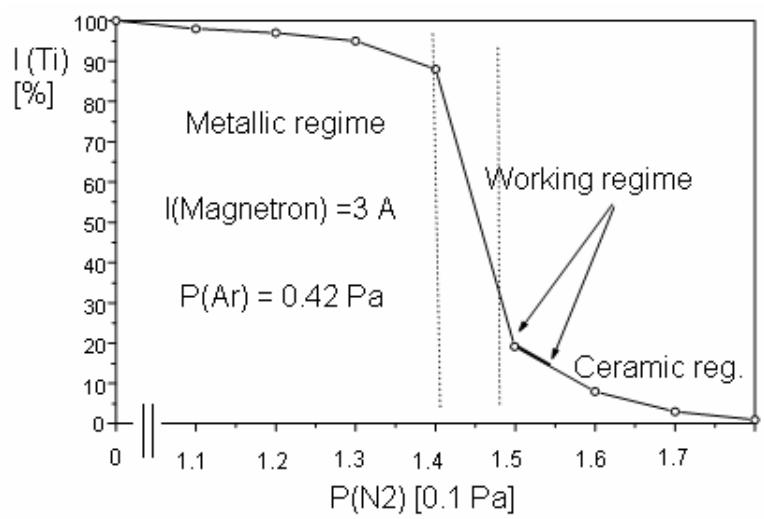

Fig. 10. Relative intensity of the $\mathrm{Ti}(\lambda=468.19 \mathrm{~nm})$ line vs. nitrogen partial pressure in the magnetron discharge

\section{Coatings' characterisation}

The chemical composition of TiN, $\mathrm{ZrN}$ and $\mathrm{ZrN} / \mathrm{TiN}$ coatings was determined by energy dispersive X-ray (EDX) spectroscopy, by means of a XL-30-ESEM TMP scanning electron microscope.

The coatings' texture, phase composition and bilayer period $\Lambda$ were determined by high angle X-ray diffraction (XRD), with $\mathrm{Cu} \mathrm{K}_{\mathrm{a}}$ radiation, using a Rigaku MiniFlex II device.

Auger electron spectroscopy (AES) technique was used to determine the elemental composition of the films by using a PHI Model 3017 AES PC-Based System, equipped with an ion gun (for sputter cleaning and etching) in the range $3 \div 5 \mathrm{keV}$. The N/Ti ratio was determined from the positive slope of the nitrogen line located at $377 \mathrm{eV}$ and the negative slope of the Ti peak at $418 \mathrm{eV}$.

The coatings' resistance to ion beam bombardment $\left(5 \mathrm{keV}, \mathrm{Ar}^{+}\right)$was done in the AES system, using a collimated ion gun for in-depth analyses. The assessment was done by surface roughness evaluation by AFM.

Films thicknesses were determined by a surface profilometer - Dektak 150. The surface morphology was observed by an atomic force probe microscope Veeco - Innova AFM/SPM, operating in tapping mode.

RBS spectra were obtained using a $2.7 \mathrm{MeV} \mathrm{He}^{+}$ion beam, revealing the elemental composition and the modulation periodicity of the multilayer, with $\Lambda$ bilayer values ranging from 80 to $160 \mathrm{~nm}$. The backscattered particles were detected by surface barrier detectors placed at $165^{\circ}$ to the beam direction.

The deposited samples were measured for their reflectivity in the range $\lambda \in[11,17] \mathrm{nm}$ at the synchrotron facility from the National Institute of Standards and Technology [NIST, 2009].

Microhardness (Vickers) measurements were performed with a microhardness tester at 0.15 $\mathrm{N}$ load. Scratch tests under standard conditions $\left(10 \mathrm{~N} / \mathrm{min}^{*} \mathrm{~mm}\right)$, using an indentor tip with electronic control of $\mathrm{x}, \mathrm{y}, \mathrm{z}$ position, were done to estimate the coatings adhesion. The critical load $\left(\mathrm{L}_{\mathrm{c}}\right)$ values were determined by optical microscopy, $\mathrm{L}_{\mathrm{c}}$ being defined as the load where film flaking starts. 
Typical EDX spectra are shown in figures 11 - 13. The elemental composition of the films, as resulted from the EDX analyses, is presented in Table 1. It can be seen that the single layer coatings are almost stoichiometric: $\mathrm{N} / \mathrm{Zr}=0.9 ; \mathrm{N} / \mathrm{Ti}=1.1$. The presence of a small amount of oxygen is probably due to the contamination during sample handling in open atmosphere before the composition analysis. For the multilayer, the EDX analysis revealed a much higher $\mathrm{Zr}$ content as compared with that of the Ti. This result is due to the differences in the $\mathrm{ZrN}$ and TiN individual layer thicknesses [Braic et al., 2006].

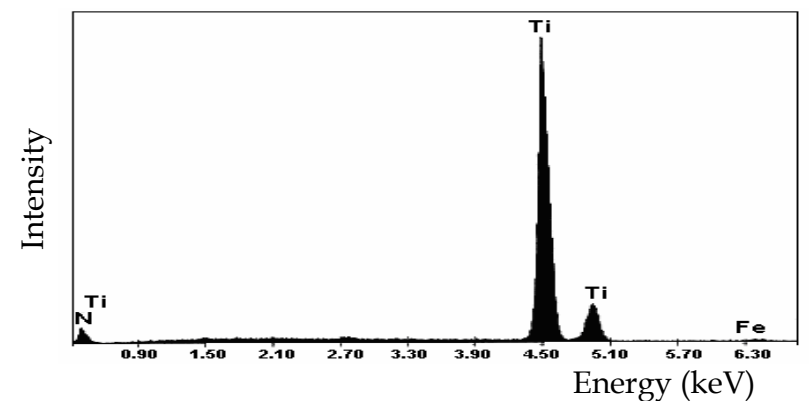

Fig. 11. EDX spectrum for a TiN coating

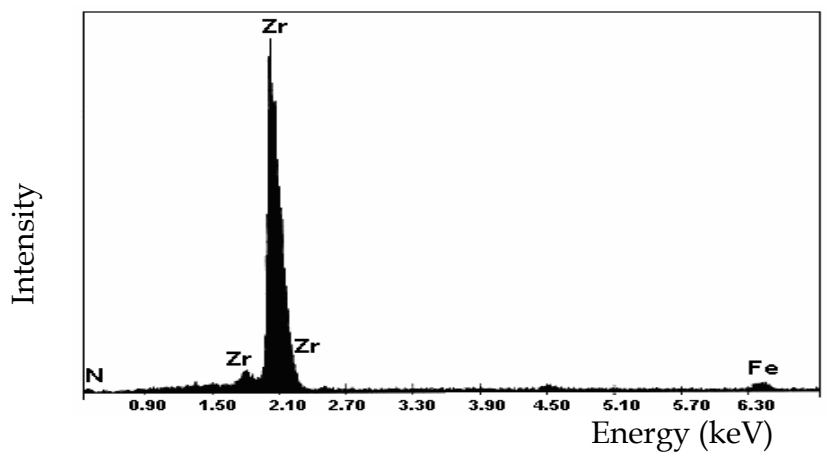

Fig. 12. EDX spectrum for a $\mathrm{ZrN}$ coating

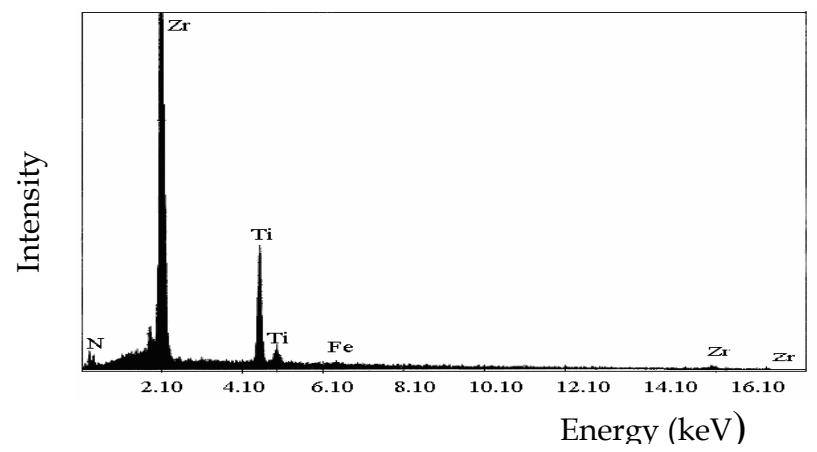

Fig. 13. EDX spectrum for a $\mathrm{ZrN} / \mathrm{TiN}$ multilayer coating 


\begin{tabular}{|c|c|c|c|c|c|}
\hline \multirow{2}{*}{ Film type } & \multicolumn{5}{|c|}{ Elemental concentration (at.\%) } \\
\cline { 2 - 6 } & $\mathrm{Ti}$ & $\mathrm{Zr}$ & $\mathrm{Fe}$ & $\mathrm{N}$ & $\mathrm{O}$ \\
\hline $\mathrm{TiN}$ & 44.9 & - & 0.7 & 51 & 3.4 \\
\hline $\mathrm{ZrN}$ & - & 49.6 & 0.9 & 44.8 & 4.7 \\
\hline $\mathrm{TiN} / \mathrm{ZrN}-900 / 7$ & 15.8 & 31.1 & 0.7 & 48.1 & 4.1 \\
\hline
\end{tabular}

Table 1. Elemental composition of $\mathrm{TiN}$ and $\mathrm{ZrN}$ coatings

Three typical diffraction patterns of $\mathrm{ZrN} / \mathrm{TiN}$ multilayer deposited on optical glass with different bilayer periods $\Lambda$ are shown in Fig. 14a, 14b and 14c. As in the case of the single layer coatings (TiN - Fig. 15 and $\mathrm{ZrN}$ - Fig. 16), the diffraction patterns for the multilayer exhibit a strong (111) preferred orientation.

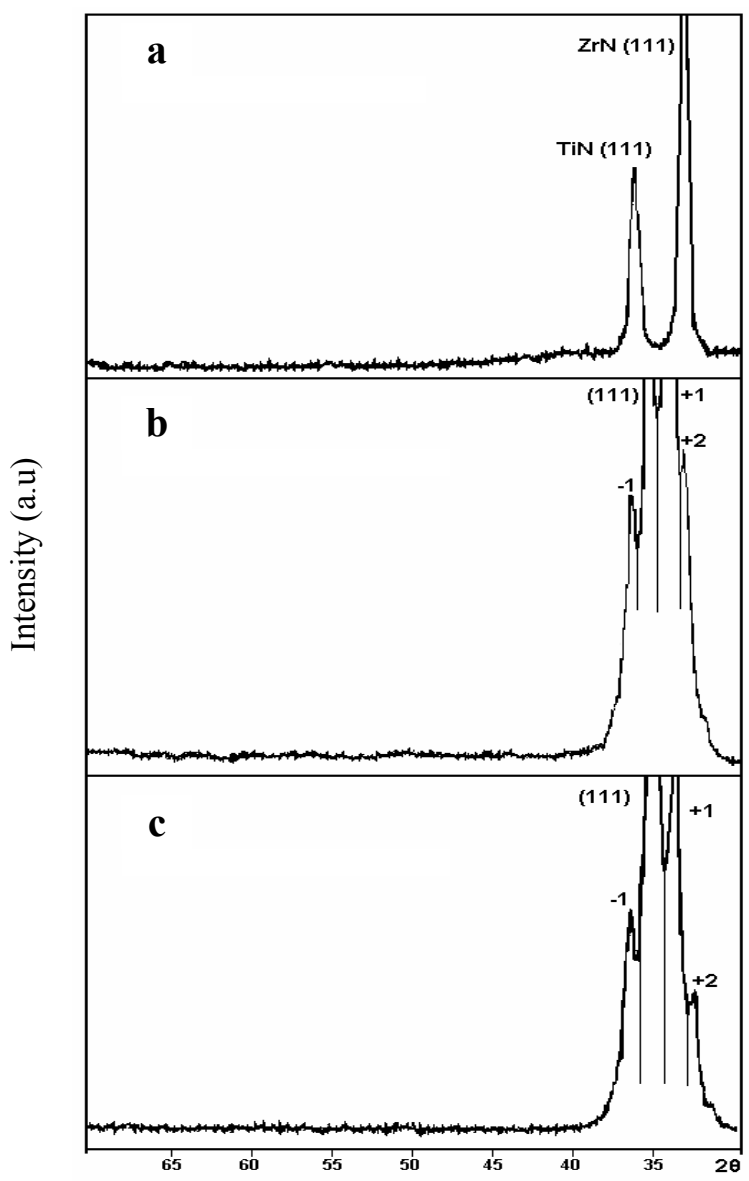

Fig. 14. X-ray diffraction patterns for $\mathrm{ZrN} / \mathrm{TiN}$ multilayer

For the ZrN/TiN ML coatings with a large bilayer period $(\Lambda=550 \mathrm{~nm}$, Fig. 14a), the diffraction lines belong both to the $\mathrm{ZrN}$ and to the TiN films, from which the coating is 
composed. It is worth to note that the diffraction pattern is not similar with that exhibited by a TiZrN layer (Fig. 17).

For the nanometre scale $\mathrm{ZrN} / \mathrm{TiN}$ multilayer $(\Lambda<10 \mathrm{~nm})$, the pattern generally consists of a Bragg peak located at the average lattice spacing of the multilayer surrounded by equally spaced satellite peaks, as can be seen in Fig. 14b and Fig. 14c. The bilayer period $\Lambda$ was calculated, as in ref. [Yashar \& Sproul, 1999], from:

$$
\sin \theta_{ \pm}=\sin \theta_{B} \pm \frac{m \lambda}{2 \Lambda}
$$

where $\theta_{ \pm}$are the positions of the m-th order positive $(+)$and negative $(-)$satellite peaks, $\theta_{\mathrm{B}}$ is the position of the main Bragg reflection and the $\lambda$ is the $X$-ray wavelength.

In the cases illustrated in figures $14 \mathrm{~b}$ and $14 \mathrm{c}$, the calculations lead to the $\Lambda$ values of $9.2 \mathrm{~nm}$ and $7.2 \mathrm{~nm}$, in excellent agreement with the values determined from the measurement of coating overall thickness and deposition time $(9.1 \mathrm{~nm}$ and $7.0 \mathrm{~nm})$.

The AES analyses were done on ZrN (Fig. 18a), TiN (Fig.18b) and TiZrN (Fig.19) mono layers, in order to obtain the specific pattern of the individual layers in multi-layered structure and also of the possible mixture of them. For this purpose, in order to have a clear answer, there were investigated multi-layers with two large $\Lambda$ values (40 and $180 \mathrm{~nm}$ ) and $\Gamma$ $=0.5$. The multilayers with high $\Lambda$ values were studied in order to determine the etching rate of TiN and $\mathrm{ZrN}$ layers. The elemental analyses were done after cleaning the surface by ion bombardment etching $\left(\mathrm{Ar}^{+}, 3 \mathrm{keV}\right)$ for $10 \mathrm{~min}$.

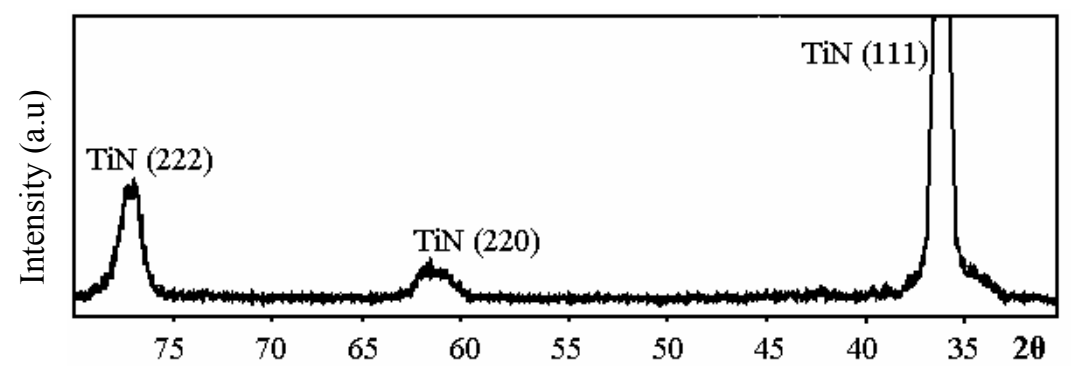

Fig. 15. X-ray diffraction patterns for $\mathrm{TiN}$

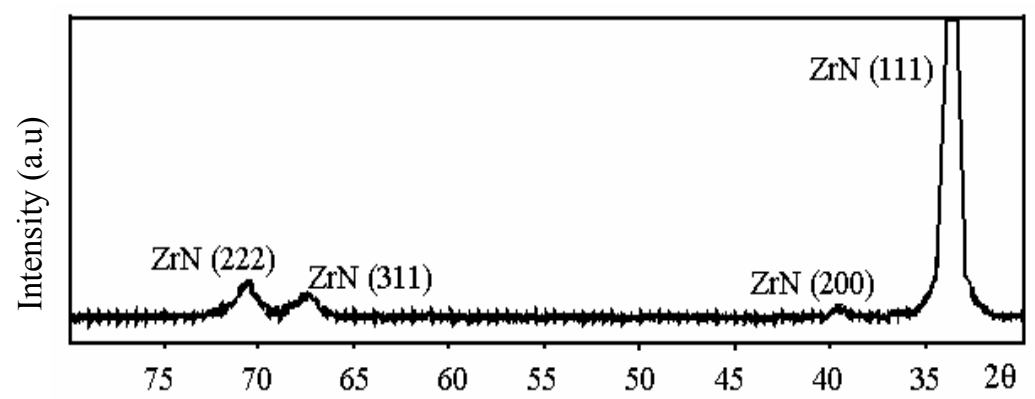

Fig. 16. X-ray diffraction patterns for $\mathrm{ZrN}$ 


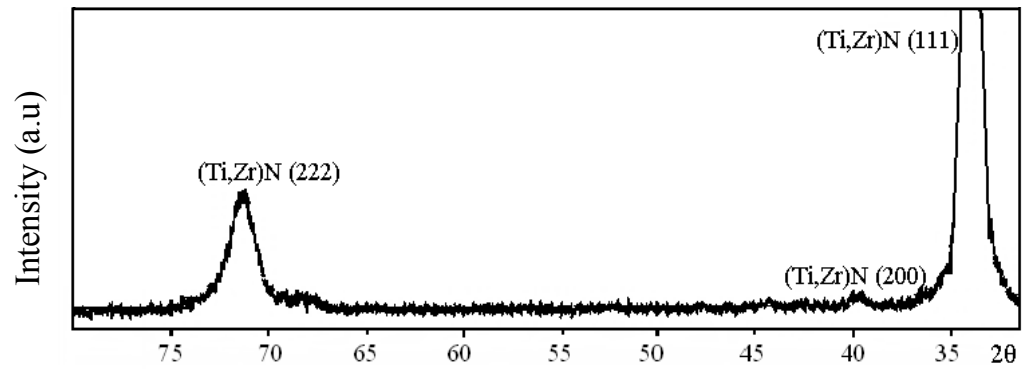

Fig. 17. X-ray diffraction patterns for $(\mathrm{Ti}, \mathrm{Zr}) \mathrm{N}$

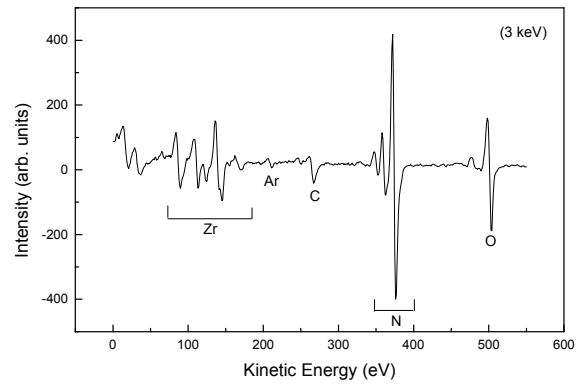

(a)

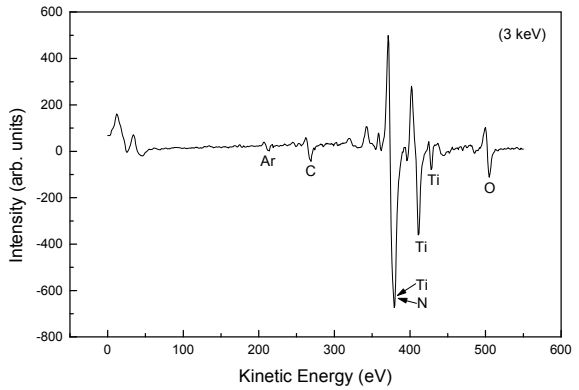

(b)

Fig. 18. Elemental composition done by AES of $\mathrm{ZrN}(\mathrm{a})$ and $\mathrm{TiN}(\mathrm{b})$ stoichiometric single layers

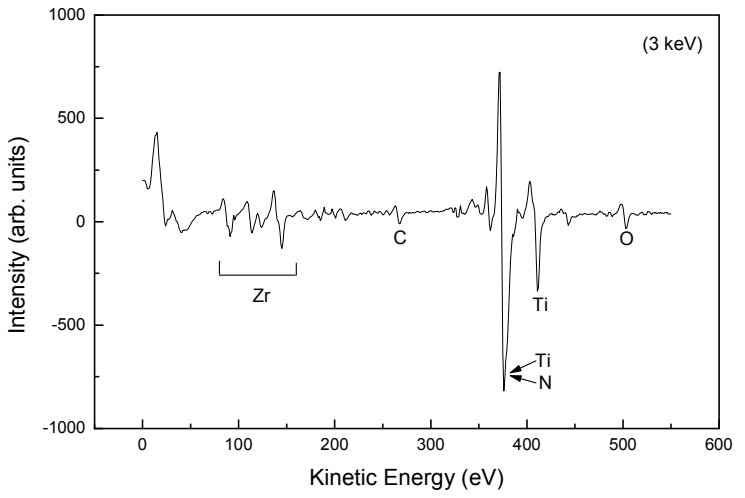

Fig. 19. Elemental composition done by AES of ZrTiN single layers ( $\mathrm{Zr}: \mathrm{Ti}=1.0)$

For the ML structure with $\Lambda=40 \mathrm{~nm}$ and $\Gamma=0.5$, AES signature of the top ZrN layer is presented in Fig. 20a, while in Fig. 20b is presented the bottom TiN layer. From the analysis it results that the individual TiN and $\mathrm{ZrN}$ layers are well defined in the ML, the obtained AES patterns being practically identical with the AES patterns obtained for single layers (Figs. 18a and 18b), with no "signature" for layer intermixing. 


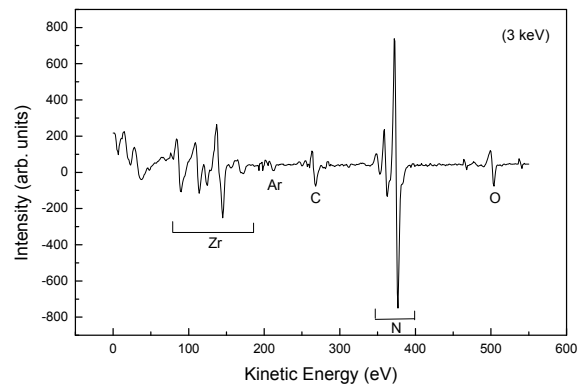

(a)

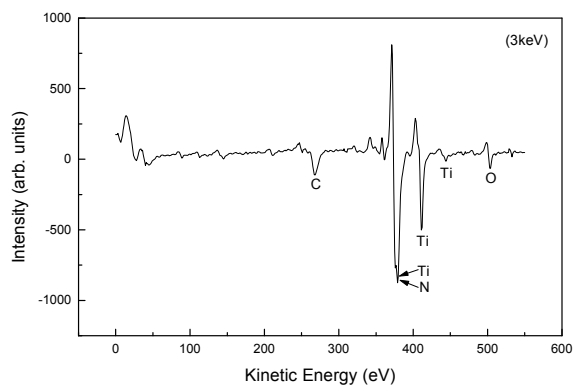

(b)

Fig. 20. AES analyses of the ZrN top layer (a) and TiN bottom layer (b) in $\mathrm{ZrN} / \mathrm{TiN}$

Selected images of some MLs deposited on $\mathrm{Si}$ and optical glass substrates are presented in Figs. 21. The roughness values of the uncoated and ML coated ( $\mathrm{n}=40 \mathrm{~nm}, \mathrm{~d}=7 \mathrm{~nm}$ ) specimens are summarized in Table 2 , where $R_{a}$ is the roughness average, $R_{q}$ is the rms roughness and $R_{t}$ is maximum height of the profile in the investigated area:

$$
\begin{aligned}
& \mathrm{R}_{\mathrm{a}}=(\mathrm{nm})=\left|\frac{\sum(\mathrm{x}-\overline{\mathrm{x}})}{\mathrm{N}}\right| \\
& \mathrm{R}_{\mathrm{q}}=(\mathrm{nm})=\sqrt{\frac{\sum(\mathrm{x}-\overline{\mathrm{x}})^{2}}{\mathrm{~N}}} \\
& \mathrm{R}_{\mathrm{t}}=(\mathrm{nm})=\mathrm{x}_{\text {Max. }}-\mathrm{x}_{\text {min }} .
\end{aligned}
$$

These results do not show any changes in the roughness of coated surfaces as compared with uncoated ones. The experiments showed that the increase of the number of bilayers $n$, accompanied by the overall thickness increase, lead to roughness increase. A comparison between the roughness of ML coatings with different thickness - as resulting from variations in the number of bilayers, is presented in Table 3.

\begin{tabular}{|c|c|c|c|c|}
\hline Roughness parameters & $\mathrm{Si}$ & Glass & ML/Si & ML/glass \\
\hline $\mathrm{R}_{\mathrm{a}}(\mathrm{nm})$ & 0.5 & 0.5 & 0.5 & 0.5 \\
\hline $\mathrm{R}_{\mathrm{q}}(\mathrm{nm})$ & 0.5 & 0.5 & 0.5 & 0.6 \\
\hline $\mathrm{R}_{\mathrm{t}}(\mathrm{nm})$ & 10.3 & 11.8 & 10.9 & 9.0 \\
\hline
\end{tabular}

Table 3. AFM determined roughness for uncoated and $\mathrm{ZrN} / \mathrm{TiN}-40 / 7$ coated specimens

\begin{tabular}{|c|c|c|c|c|}
\hline \multirow{2}{*}{ Roughness parameters } & \multicolumn{2}{|c|}{ ML/Si } & \multicolumn{2}{c|}{ ML/glass } \\
\cline { 2 - 5 } & $\mathrm{n}=100$ & $\mathrm{~N}=40$ & $\mathrm{n}=100$ & $\mathrm{n}=40$ \\
\hline $\mathrm{R}_{\mathrm{a}}( \pm 0,5 \mathrm{~nm})$ & 1,0 & 0,5 & 0,8 & 0,5 \\
\hline $\mathrm{R}_{\mathrm{q}}( \pm 0,5 \mathrm{~nm})$ & 1,4 & 0,5 & 1,2 & 0,6 \\
\hline $\mathrm{R}_{\mathrm{t}}( \pm 0,5 \mathrm{~nm})$ & 27,9 & 10,9 & 26,8 & 9,0 \\
\hline
\end{tabular}

Table 4. AFM determined roughness for uncoated and $\mathrm{ZrN} / \mathrm{TiN}-40 / 7$ coated specimens 


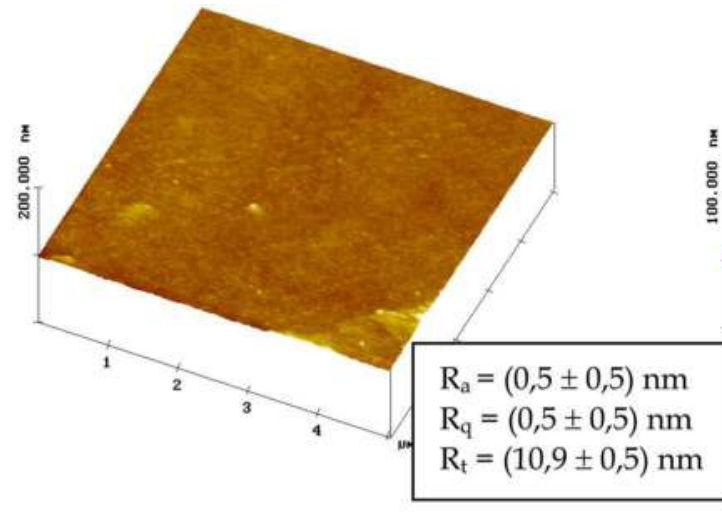

(a)

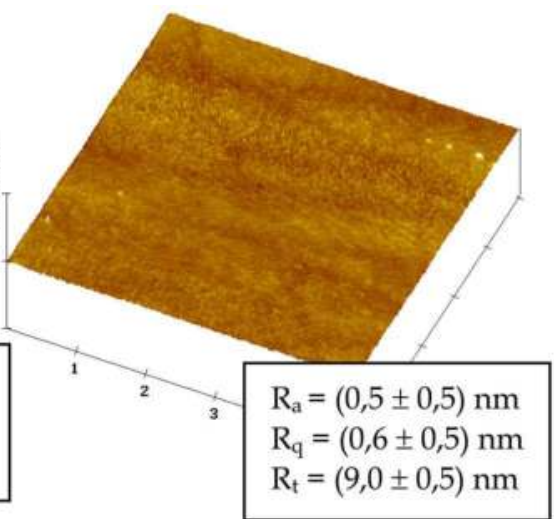

(b)

Fig. 21. ZrN/TiN-40/7 films deposited on Si (a) and on optical glass (b)

For the assessment of ion beam damage induced on coatings, relatively thick $\mathrm{ZrN}$ monolayered films were used $(800 \mathrm{~nm})$, as it is important that the top layer with the highest EUV reflectivity to be preserved. The averaged roughness values $R_{a}$ decreased from the initial value of $1.1 \mathrm{~nm}$ to $0.8 \mathrm{~nm}$, after ion bombardment with $5 \mathrm{keV} \mathrm{Ar}+$ ions, for 30 minutes. The RBS spectra of the ZrN/TiN multilayer $\mathrm{n}=5, \Lambda=80 \mathrm{~nm}, \Gamma=0.5$, presented in Fig. 22, are experimental data and simulated curves. For the coatings with large bilayer periods (80 $160 \mathrm{~nm}$ ), a good agreement between the experimental and theoretical curves was obtained. The individual layers may be clearly distinguished and their thicknesses were accurately determined. On the other hand, the in-depth resolution of the method does not allow observing the multilayer structure for bilayer periods less than $40 \mathrm{~nm}$. The aim of the presented BRS analyses was to evidence the well structured multilayered coatings.

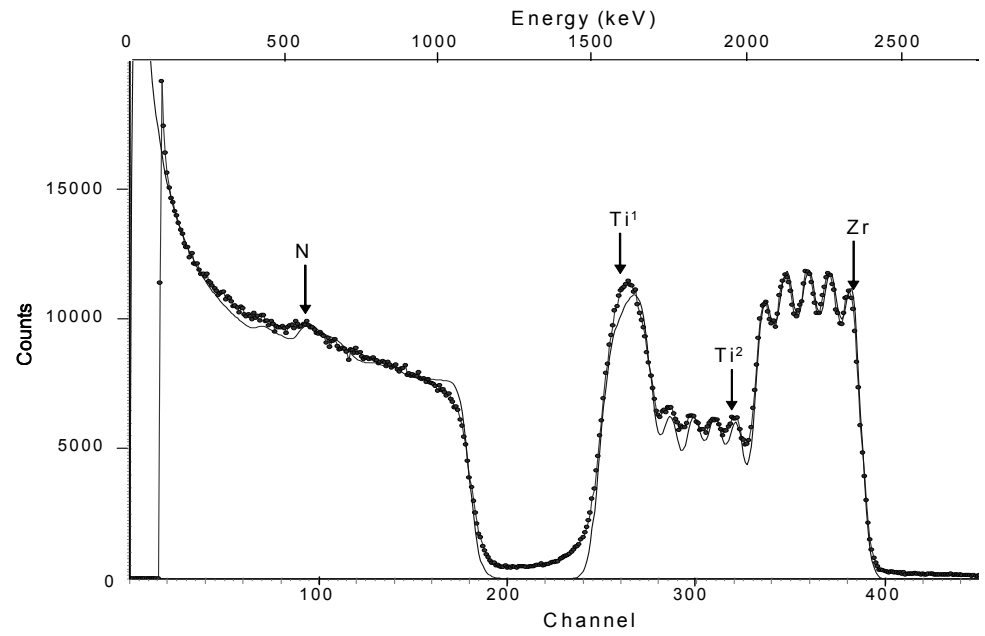

Fig. 22. RBS spectrum from a $\mathrm{ZrN} / \mathrm{TiN}$ multilayer; $\mathrm{n}=5 ; \Lambda=80 \mathrm{~nm}, \Gamma=0.5$ (experimentalthick line; simulated data-thin line) 
For the $\mathrm{ZrN} / \mathrm{TiN}-40 / 7 \mathrm{ML}$ type, the measured reflectivity at $\lambda=13.5 \mathrm{~nm}$, at grazing incidence angles ranging from $6^{\circ}$ to $15^{\circ}$ (Fig. 23) proved to be in good agreement with the values obtained by modelling (Fig. 5).

The observed decreasing of the EUV reflectivity, as compared to the ideal values, is due to the surface contamination in open air during sample manipulation.

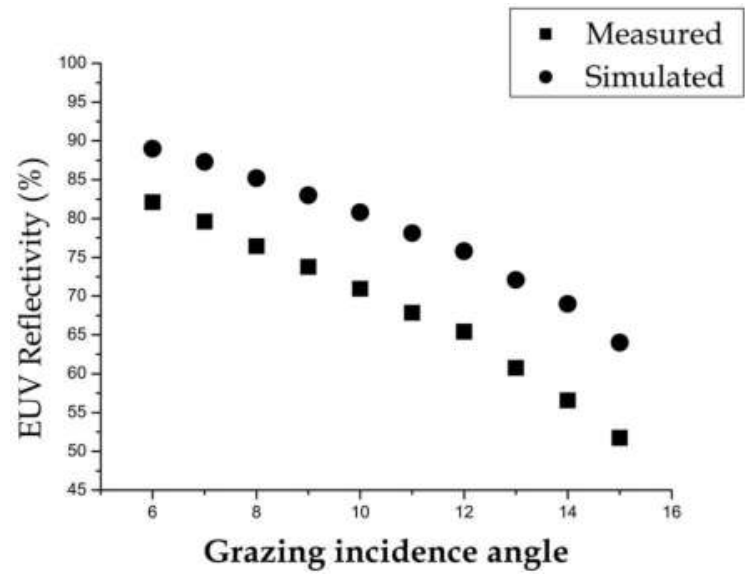

Fig. 23. Simulated (modelled) and measured reflectivity of $\mathrm{ZrN} / \mathrm{TiN} / 40 / 7$ samples at $6^{\circ}-$ $15^{\circ}$ grazing incidence angles at $\lambda=13.5 \mathrm{~nm}$

The microhardness and critical load $\left(\mathrm{L}_{\mathrm{c}}\right)$ values of different coatings, when deposited on high-speed steel substrates are given in Table 5.

The existence of a narrow range of $\Lambda$ values for which the hardness reaches its maximum value was already found for other ML with low $\Lambda$ values, also known as superlattices [Shih \& Dove, 1992], [Yang et al., 2002], [Barshilia et al., 2006], [Balaceanu et al., 2005],[Braic at al., 2006], [Abadias et al., 2007], being explained as the result of the combined effects of different strengthening mechanisms as Hall-Petch and Koehler models, coherency strain effects [Helmersson et al., 1987], [Yashar \& Sproul, 1999], [Musil, 2000].

\begin{tabular}{|c|c|c|}
\hline Coating & $\mathrm{HV}_{0.015}(\mathrm{GPa})$ & $\mathrm{L}_{\mathrm{c}}(\mathrm{N})$ \\
\hline $\mathrm{TiN}$ & 24 & 48 \\
\hline $\mathrm{ZrN}$ & 21 & 56 \\
\hline $\mathrm{ZrTiN}$ & 28 & 47 \\
\hline $\mathrm{ZrN} / \mathrm{TiN}-1100 / 6$ & 23 & 52 \\
\hline $\mathrm{ZrN} / \mathrm{TiN}-700 / 9$ & 34 & 58 \\
\hline ZrN/TiN - 900/7 & 35 & 57 \\
\hline
\end{tabular}

Table 5. Mechanical characteristics of the films

As for the adhesion, the critical failure loads $\mathrm{L}_{\mathrm{c}}$ for the monolayers in the scratch test were in the range of $47-56 \mathrm{~N}$, the highest value being measured for $\mathrm{ZrN}$ layer. A higher adhesion strength was found for the $\mathrm{ZrN} / \mathrm{TiN}-700 / 9$ coatings $\left(\mathrm{L}_{\mathrm{c}}=58 \mathrm{~N}\right)$. The result might be accounted for by the reduction in residual stress by the multilayered structure, as commonly reported for various multilayers, e.g. [Oh \& Je, 1993]. It can also be seen that the adhesion 
decreased with decreasing bilayer period. This finding could be attributed to the role played by the interfacial bonding, coherency strain and interfacial delamination [Abadias et al., 2007], which is more pronounced as the number of layers, and hence interfaces, increases.

\section{Conclusions}

$\mathrm{ZrN} / \mathrm{TiN}$ reflective hard coatings with bilayer periods $\Lambda$ ranging in the nanometre range were successfully deposited on $\mathrm{Si}$, optical glass and other test substrates using the pulsed bipolar magnetron sputtering method. The monolayer films of $\mathrm{ZrN}$ and TiN were almost stoichiometric $(\mathrm{N} / \mathrm{Zr}=0.9$ and $\mathrm{N} / \mathrm{Ti}=1.1)$. The XRD patterns of the ML with small $\Lambda$ values exhibited a pattern typical for superlattice coatings, consisting of a main Bragg peak surrounded by satellite peaks. Ion bombardment $(5 \mathrm{keV} \mathrm{Ar})$ of the MLs, intended to mimic the bombardment with EUV source debris, showed for the $\mathrm{ZrN}$ layer a slight decrease of the rms roughness with $0.3 \mathrm{~nm}$ after 30 minutes of ion bombardment. The multilayers with bilayer period $\Lambda$ in the $7-9 \mathrm{~nm}$ range were the hardest ( $35 \mathrm{GPa})$ and exhibited the best substrate adhesion, but good adhesion values were obtained for all the other coatings as well. The deposited films with a multilayered architecture led to an enhanced ion bombardment resistance, presenting promising reflectivity values for $13.5 \mathrm{~nm}$ EUV radiation. The obtaining of dense, adherent and highly reflective coatings for grazing incidence is a valuable research direction, using the bipolar pulsed magnetron sputtering deposition method.

As future challenges, a diversity of problems such as the ability to create a reliable high power EUV source, the maintenance of EUV mirrors through the use of debris mitigation schemes and the cleaning of contaminants, the development of a resist with low line edge roughness, and of a defect-free EUV mask, need to be solved. Each challenge needs to be overcome for EUVL to be a viable candidate for high volume manufacturing. The combination of efficient debris mitigation schemes, innovative methods for mirrors quick cleaning in adequate gases, as well as new coatings with high toughness, high adhesion and chemical inertness will provide the optimal design for EUVL systems, as reliable tools for a cost effective process for the mass production of nano-electronics components.

\section{Acknowledgement}

The work was supported under the European project SOARING, National Kern Projects TINOSOL and OPTOSOL.

The authors want to kindly acknowledge the help of Dr. Fred Bijkerk (FOM-Netherlands) for EUV reflectance measurements.

\section{References}

Abadias, G., Michel, A.S., Tromas, C., Jaouen, C. and Dub, S.N. (2007). Stress, interfacial effects and mechanical properties of nanoscale multilayered coatings, Surface and Coatings Technology, 202, 24 May 2007, pp: 844-853, ISSN 0257-8972

Allain, P.P., Nieto, M., Hassanein, A. (2008) Specular reflectivity of 13.5-nm light from Sn islands deposited on grazing incidence mirror surfaces, Applied Physics, Vol. A 91, April 2008, pp: 13-16 ISSN 0947-8396 
Alman, D.A., Qiu, H., Spila, T., Thompson, K.C., Antonsen, E.L., Jurczyk, B.E. and Ruzic, N.D. (2007). Characterization of collector optic material samples exposed to a discharge-produced plasma extreme ultraviolet light source, J. Micro-Nanolith. MEMS MOEMS, Vol. 6, pp:013006.1-013006.5, ISSN 1817-6461

ASML (2009) http://www.asml.com/euv/asml_160_technical.html.

Bakshi, V. (2006), EUV Sources for Lithography, Vol: PM149, 23 February 2006, SPIE Press Book, ISBN: 9780819458452

Balaceanu, M., Braic, M, Braic, V. and Pavelescu, G. (2005). Properties of arc plasma deposited TiCN/ZrCN superlattices coatings, Surface and Coatings Technology, Vol. 200, Issues 1-4 , 1 Oct. 2005, pp:1084-1087; ISSN 0257-897

Balaceanu, M., Braic, M., Braic, V., Negrila, C.C. (2005). Surface chemistry of plasma deposited ZrC hard coatings, J.Optoel. Adv.Mat., Vol. 7/5, pp: 2557-2560, ISSN 1454-4164

Banine, V., Moors, R. (2004). Plasma sources for EUV lithography exposure tools, J. Phys. D Appl. Phys. Vol. 37 Dec.2004, pp: 3207-3212, ISSN 0022-3727

Barshilia, H. C. and Rajam, K.S. (2006). Reactive sputtering of hard nitride coatings using asymmetric-bipolar pulsed DC generator, Surface and Coatings Technology, Volume 201, Issues 3-4, 5 oct. 2006, pp: 1827-1835, ISSN 0257-8972

Barshilia,H.C., Rajam, K.S., Jain, A., Gopinadhan, K. and Chaudhary, S. (2006), A comparative study of the structure and properties of the nanolayered $\mathrm{TiN} / \mathrm{NbN}$ and TiAlN/TiN multilayered coatings prepared by reactive direct current magnetron deposition, Thin Solid Films, Vol.503 May 2006, pp: 158 - 166 ; ISSN 00406090

Benoit, N., Yulin, S., Feigl, T., Kaisers, N. (2006). EUV multilayer mirrors with enhanced stability, Proceedings of the SPIE, Vol.6317, Aug.2006, no. 63170K, ISSN 0277-786X.

Bollanti, S., Bonfigli, F., Burattini, E., Di Lazzaro, P., Flora, F., Grilli, A., Letardi, T., Lisi, N., Marinai, A., Mezi, L., Murra, D. and Zheng, C. (2003). High-efficiency clean EUV plasma source at 10-30 nm, driven by a long-pulse-width excimer laser, Applied Physics B: Lasers and Optics, Volume 76, Number 3 / March, 2003, pp: 277-284, ISSN 0946-2171

Braic, M., Choi, P., Dumitrescu, C., Balaceanu, M., Braic, V. (2004). ZrN/TiN multilayers as debris shields for EUV mirrors grown by magnetron sputtering, IX Int. Conf. on Plasma Surface Engineering, Garmisch-Partenkirchen, Germany, 13 - 17 Sept., 2004

Braic, M., Balaceanu, M., Kiss, A., Vladescu, A., Braic, V. (2005). Zr based hard coatings as EUV grazing collection mirrors in EUV lithography Fourteenth International Summer School on Vacuum, Electron and Ion Technologies, VEIT 2005, Abstracts, pag. 77-78, 12-16 September 2005, Sunny Beach, Bulgaria

Braic, M., Balaceanu, M., Vladescu, A. , Kiss, A., Braic, V., Purice, A., Dinescu, G., Scarisoreanu, N., Stokker-Cheregi, F., Moldovan, A., Birjega, R. and Dinescu, M. (2006). TiN/ZrN heterostructures deposition and characterisation, Surface and Coatings Technology, Volume 200, Issues 22-23, 20 June 2006, pp: 6505-6510, ISSN 0257-8972 
Braic, V., Balaceanu, M., Braic, M. (2008) Grazing incidence mirrors for EUV lithography, Intl. Semiconductor Conf. Proceedings, pp: 267-270, IEEE Catalog no. CFP08CAS-PRT, ISBN: 9781424420049

Braic, M., Braic, V., Balaceanu, M., Thin film reflectors for EUV (10-20 nm) radiation, Romanian Patent no.6/004/2009

Choi, P., Aliaga-Rossel, R., Braic, V., Braic, M., Dumitrescu, C., Leblanc, C., Mengtong, Q., Novikov, V.G., Ware, K.D., Yuan, A., Zakharov, S., Zakharov, V., Zhen, L. (2004). The SOARING. Micro Plasma Pulse Discharge EUV Source., Sematech-Lithography Meetings, EUV Source Workshop, Santa Clara, California, USA, 22 February 2004, http://internationalsematech.org/meetings/archives/litho/euvl/20040222b/post ers/18Choi.pdf

CXRO (2009) http://henke.lbl.gov/optical_constants/

Ducros C. and Sanchette, F. (2006). Multilayered and nanolayered hard nitride thin films deposited by cathodic arc evaporation - Mechanical properties and cutting performances, Surface and Coatings Technology, Volume 201, Issues 3-4, 5 October 2006, pp:1045-1052, ISSN 0257-8972

Feigl, T., Yulin, S., Benoit, N. and Kaiser, N. (2006). EUV multilayer optics, Microelectron. Eng. Vol. 83, pp: 703-706, ISSN 0167-9317

Fiedorowicz, H., Bartnik, A., Jarocki, R., Kostecki, J., Krzywiński, J., Mikołajczyk, J., Rakowski, R., Szczurek A. and Szczurek, M. (2005). Compact laser plasma EUV source based on a gas puff target for metrology applications, Journal of Alloys and Compounds, Volume 401, Issues 1-2, 29 September 2005, pp: 99-103, ISSN 0925-8388

Hequet, C., Ravet-Krill, M.-F., Delmotte, F., Jerome , A., Hardouin, A., Bridou, F., Arniere, F., Roulliay, M., Bourcier, F., Desmarres, J.-M., Costes, V., Berthon, J., Rinchet, A. and Geyl, R. (2007). Design, conception and metrology of EUV mirrors for aggressive environments, Proceedings of SPIE, vol. 6586, pp. 65860X.1-65860X.10, Damage to VUV, EUV, and X-ray optics Meeting, 18-19 April 2007, Prague, Czech Republic, ISSN 0277-786X

Helmersson, U., Todorova, S., Barnett, S.A., Sundgren, J.E., Markert, L.C. and Greene, J.E. (1987). Growth of single-crystal TiN/VN strained-layer superlattices with extremely high mechanical hardness , J. Appl. Phys., Vol. 62 Jul1987, pp: 481 - 484; ISSN 0021-8979

Hubbell, J.H., Veigele, W.J., Briggs, E.A., Brown, R.T., Cromer, D.T. and Howerton, R.J. (1975), Atomic Form Factors, Incoherent Scattering Functions, and Photon Scattering Cross Sections, J. Phys. Chem. Ref. Data, Vol.4, pp: 471-538 ; ISSN 00472689

Hubbell, J.H., Veigele, W.J., Briggs, E.A., Brown, R.T., Cromer, D.T. and Howerton, R.J. (1977), Erratum at Atomic Form Factors, Incoherent Scattering Functions, and Photon Scattering Cross Sections, J. Phys. Chem. Ref. Data, Vol.6, pp: 615-616, ISSN 0047-2689

Hugosson, H.W., Eriksson, O., Jansson, U., and Johansson, B. (2001), Phase stabilities and homogeneity ranges in 4d-transition-metal carbides: A theoretical study, Phys.Rev.B. Vol. 63 March 2001,pp: 134108.1 - 134108.11, ISSN 0163-1829. 
Glocker, D., Ismat Shah, S., Editors, Spiller,E.,-author (1995). Handbook of Thin film Process Technology, F5 - Multilayered structures for X Ray mirrors, IOP Publishing, ISBN 0 75030311 5, Bristol, UK

Itani, T. (2009) Recent status and future direction of EUV resist technology, Microelectronic Engineering, Volume 86, Issue 3, March 2009, pp: 207-212, ISSN 0167-9317

Jaeger, R. C., (2002), Lithography-Introduction to Microelectronic Fabrication, ISBN 0-201-444947, Upper Saddle River: Prentice Hall

Kanoun, M.B., Goumri-Said, S. and Jaouen, M. (2007). Structure and mechanical stability of molybdenum nitrides: A first-principles study, Phys. Rev. B, Vol. 76, pp: 134109.1134109.4 , ISSN 0163-1829

Lebert, R., Juschkin, L., Jägle, B., Meisen, M., Berman, V., Bieberle U. (2003). Inband EUV Open Frame Resist Exposer TEUVL, International EUVL Symposium, 30.9.-2.10.2003, Antwerp, Belgium

Meiling, H., Banine, V., Kurz, P., Blum, B., Heerens, G. and Harned, N (2003).The EUV program at ASML: an update, Proceedings of the SPIE, Vol. 5037 June 2003, pp: 2435, ISSN 0277-786X.

Meiling,H., Banine, V., Harned, N., Blum, B., Kürz, P. and Meijer, H. (2005). Development of the ASML EUV alpha demo tool, Emerging Lithographic Technologies IX. Ed. by Mackay, R. Scott. Proceedings of the SPIE, Vol. 5751 May 2005, pp. 90-101, ISSN 0277-786X.

Musil, J. (2000), Superhard nanocomposite coatings, Surface and Coatings Technology, Vol. 125 March 2000, pp: 322 - 330. ISSN 0257-8972

Neumann, M.J., DeFrees, R.A., Qiu, H., Ruzic, D.N, Khodykin, O., Ershov, A. and Bristol, R.L. (2007). Plasma cleaning of lithium off of collector optics material for use in extreme ultraviolet lithography applications, J. Micro-Nanolith. MEMS MOEMS, Volume 6, Issue 2, 2007, pp: 023005.1- 023005.8 2007, ISSN 1817-6461

NIST. (2009). http:// physics.nist.gov/MajResFac/euv.html

Oh, U.C. and Je, J.H. (1993). Effects of strain energy on the preferred orientation of tin thin films, Journal of Applied Physics, 74, 1 August 1993, pp. 1692-1696, ISSN 0021-8979

Rothschild, M., Bloomstein, T.M., Efremow, N.Jr., Fedynyshyn, T.H., Fritze, M., Pottebaum, I. and Switkes, M. (2005). Nanopatterning with UV Optical Lithograpy. MRS Bull. Vol.30 Dec. 2005, pp: 942-946, ISSN 0883 - 7694

Schroeder, S., Feigl, T., Duparre, A. and Tuennermann, A. (2007). EUV reflectance and scattering of Mo/Si multilayers on differently polished substrates, Optics Express, Vol. 15, Issue 21, pp. 13997-14012, 11 October 2007, ISSN: 1094-4087

SEMATECH.(2009). http://www.sematech.org/corporate/news/releases/20090211.htm

Shih, K.K. and Dove, D.B. (1992), Ti/Ti-N Hf/Hf-N and W/W-N multilayer films with high mechanical hardness, Applied Physics Letters, Vol. 61 Aug. 1992, pp: 654 - 656, ISSN 0003-6951

Shin, H., Sporre, J.R., Raju, R. and Ruzic, D.N. (2009), Reflectivity degradation of grazingincident EUV mirrors by EUV exposure and carbon contamination, Microelectronic Engineering, Volume 86, Issue 1, January 2009, pp: 99-105, ISSN 0167-9317

Song, I., Kobayashi, Y., Sakamoto, T., Mohanty, S.R., Watanabe, M., Okino, A., Kawamura, T., Yasuoka, K., Horioka K. and Hotta, E. (2006). Performance of gas jet type Z- 
pinch plasma light source for EUV lithography, Microelectronic Engineering, Volume 83, Issues 4-9, April-September 2006, pp: 710-713, ISSN 0167-9317

Stamm, U. (2004) Extreme ultraviolet light sources for use in semiconductor lithographystate of the art and future development, J. Phys. D Appl. Phys.Vol 37 Dec. 2004, pp: 3244-3253, ISSN 0022-3727

Stulen, R. and Sweeney, D. (1999). Extreme ultraviolet lithography, IEEE J. Quantum Electron. Vol. 35, pp: 694-699, ISSN 1063-7818

Zuppella, P., Reale, A., Ritucci, A., Tucceri, P., Prezioso, S., Flora, F., Mezi , L. and Dunne, L. (2009)Spectral enhancement of a Xe-based EUV discharge plasma source, Plasma Sources Sci. Technol., 2009, pp: 025014.1-025014.18, ISSN 0963-0252

Vargas Lopez, E., Jurczyk, B.E., Jaworski, M.A., Neumann M.J. and Ruzic, D.N. (2005), Origins of debris and mitigation through a secondary RF plasma system for discharge-produced EUV sources, Microelectronic Engineering, Volume 77, Issue 2, February 2005, pp: 95-102, ISSN 0167-9317

Vladescu, A., Balaceanu, M., Braic, V., Cotrut, C., Kiss, A. and Braic, M.(2007) Effect of energy ion bombardment on characteristics of Ti based biocompatible coatings, Plasma Process. Polym., 4 (S1), S406-S410, April 2007, ISSN 1612-8850

Vladescu, A., Kiss, A., Popescu, A., Braic, M., Balaceanu, M., Braic, V., Tudor, I., Logofatu, C., Negrila, C.C. and Rapeanu, R., (2008), Influence of Bilayer Period on the Characteristics of Nanometre-Scale ZrN/TiAlN Multilayers, Journal of Nanoscience and Nanotechnology, Vol. 8, No.2, February 2008, pp: 717-721, ISSN, 1533-4880

Wallace, J., Cheng, Y.-C., Isoyan, A., Leonard, Q., Fisher, M., Green, M., Bisognano, J., Nealey, P. and Cerrina, F. (2007), A novel EUV exposure station for nanotechnology studies, Nuclear Instruments and Methods in Physics Research Section A: Accelerators, Spectrometers, Detectors and Associated Equipment, Volume 582, Issue 1, 11 November 2007, pp: 254-257, ISSN: 0168-9002

Wang, S., Zhu, J.T., Wang, F.L., Zhang, Z., Wang, H.C., Qin, S.J. and Chen, L.I. (2006) Development of Multilayer Optics for EUV, Soft X-Ray and X-Ray Regions in IPOE , Springer Proceedings in Physics - X-ray Lasers, Volume 115, pp: 401-408, Springer Netherlands, January 18, 2008, ISSN 0930-8989; ISBN 978-1-4020-6017-5

Yang, O., He, C., Zhao, L.R. and Immarigeo, J.P. (2002 ), Preffered orientation and hardness enhancement of TiN/CrN superlattices coatings deposited by reactive magnetron sputtering, Scripta Materialia, Vol.46 Feb 2002, pp: 293 - 297; ISSN 1359-6462

Yashar, P.C. and Sproul, W.D. (1999). Nanometer scale multilayered hard coatings, Vacuum, Vol.55 Dec.1999, pp: 179 - 190; ISSN 0042-207X 


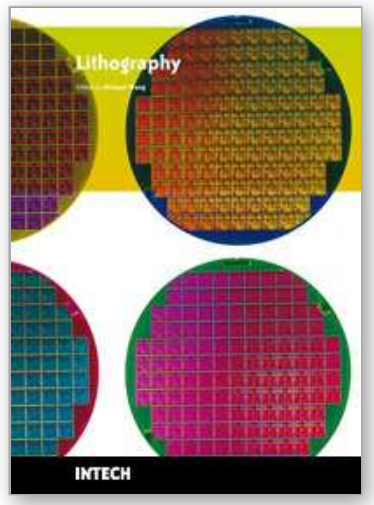

\author{
Lithography \\ Edited by Michael Wang
}

ISBN 978-953-307-064-3

Hard cover, 656 pages

Publisher InTech

Published online 01, February, 2010

Published in print edition February, 2010

Lithography, the fundamental fabrication process of semiconductor devices, plays a critical role in micro- and nano-fabrications and the revolution in high density integrated circuits. This book is the result of inspirations and contributions from many researchers worldwide. Although the inclusion of the book chapters may not be a complete representation of all lithographic arts, it does represent a good collection of contributions in this field. We hope readers will enjoy reading the book as much as we have enjoyed bringing it together. We would like to thank all contributors and authors of this book.

\title{
How to reference
}

In order to correctly reference this scholarly work, feel free to copy and paste the following:

Mariana Braic, Mihai Balaceanu and Viorel Braic (2010). Grazing Incidence Mirrors for EUV Lithography, Lithography, Michael Wang (Ed.), ISBN: 978-953-307-064-3, InTech, Available from: http://www.intechopen.com/books/lithography/grazing-incidence-mirrors-for-euv-lithography

\section{INTECH}

open science | open minds

\section{InTech Europe}

University Campus STeP Ri

Slavka Krautzeka 83/A

51000 Rijeka, Croatia

Phone: +385 (51) 770447

Fax: +385 (51) 686166

www.intechopen.com

\section{InTech China}

Unit 405, Office Block, Hotel Equatorial Shanghai

No.65, Yan An Road (West), Shanghai, 200040, China 中国上海市延安西路65号上海国际贵都大饭店办公楼 405 单元 Phone: $+86-21-62489820$

Fax: +86-21-62489821 
(C) 2010 The Author(s). Licensee IntechOpen. This chapter is distributed under the terms of the Creative Commons Attribution-NonCommercialShareAlike-3.0 License, which permits use, distribution and reproduction for non-commercial purposes, provided the original is properly cited and derivative works building on this content are distributed under the same license. 